\title{
Digital Media Behavior of School Students: Abusive Use of the Internet
}

\author{
Andrés García-Umaña ${ }^{1 *} \odot$, Ramón Tirado-Morueta² \\ ${ }^{1}$ School of Design, Sciences of Education and Communication, Pontificia Universidad Católica, Ecuador \\ \{guea@pucesd.edu.ec\} \\ 2Faculty of Education Sciences, University of Huelva, Spain \{rtirado@dedu.uhu.es\} \\ Received on 17 February 2018; revised on 19 February 2018; accepted on 16 April 2018; published on 15 July 2018
}

\begin{abstract}
The increase in the use of information technologies encompasses all educational and social issues, even changing intergenerational skills. It is considered that the most conditioned to this effect are adolescents and young people. This research is a literary review of various studies on addiction and Internet abuse and presents relevant results of the situation of college students and their level of Internet use. The study was developed in seven educational units of Ecuador, with a sample of $n=773$ students (53.6\% men and $46.4 \%$ women). An instrument with sufficient validation guarantees (a.94) has been applied, verified by means of a factorial analysis of main components, which determined two study factors in the use of the Internet and loss of control and interference with life. Through a statistical treatment (Pearson) a good correlation was established $(, 62)$ between the two study dimensions, which is a concern in the educational field.
\end{abstract}

KEYWORDS: BEHAVIOR, INTERNET, SCHOOL PERFORMANCE.

\section{INTRODUCTION}

The Internet comes from the abbreviation INTERconected NETworks, which means: interconnected networks through a communication protocol, which has transformed the way of communicating, opening new possibilities of knowledge (Mengual, Lloret \& Roig, 2013).

The Internet has been used since 1969. Disseminated twenty years later due to several factors: change in regulation, increase in broadband needs, diffusion of personal computing equipment, software improvement, access, transmission of content and the social demand of commercial networks.

Billieux \& Van der Linden (2012), compared to the Internet to a central nervous system in our community, which has evolved from web 1.0 that allowed only reading and searching for information, the content was paramount, on the other hand web 2.0 allows reading, more writing and round trip information, where the user is the most important. The network allows synchronous

\footnotetext{
*To whom correspondence should be addressed:

Vía Chone Km. 2,

Calle San Cristóbal e Isla Santa Cruz

Santo Domingo - Ecuador
}

and asynchronous communication and an environment conducive to collaborative, institutional and personal work, becoming a stimulus for global and interdisciplinary work and at the same time a common denominator between teachers and students anywhere in the world (Brand, Young \& Laier, 2014), access to an inexhaustible sea of information and knowledge of multiple cultures and languages.

However, its multiplicity of functions has made it a part of daily life and therefore, as lifestyle has been changing, this has provoked the concern of multiple researchers to determine that there is the possibility of generating behavioral addiction, especially in adolescents / the young. The consequent abuse behaviors are still defined by the American Psychiatric Association (APA) (Demetrovics \& Griffiths, 2012), although they are not yet recognized as addictive pathologies, they follow the research path of several authors (Castellanos, Sánchez, \& Calderero, 2017; Demetrovics \& Griffiths, 2012, Aesaert, et al., 2015, Jiménez-Albiar, Piqueras, Mateu-Martínez, Carballo, Orgilés \& Espada, 2012, Ruiz-Olivares, Lucena, Pino \& Herruzo, 2010).

The addictions sustain their course classifying themselves as a contrariety of behavior instead of an addiction. Young (1996) indicates that Internet addiction is a detriment to control and that it has a symptomatic display at the cognitive, behavioral and social levels; the excessive use of the Internet has consequences of distortion of personal, family and professional objectives. Colás-Bravo et al., (2017) mentions that adolescents who spend more time on the use of Internet display an emotional instability tending to introversion and pessimism.

Griffiths $(2005 ; 2012)$ suggests that this parallelism between addiction with and without psychotropic substances can be useful for the analysis and regulation of pathologies and to understand society's perception of these behaviors. The investigation of Internet addiction arises through two issues: as an addiction in itself and as the channel that allows the growth of multiple addictions (sex, shopping, social networks, among others). Carbonell, Fuster, Chamarro, \& Oberts (2012) verify that problematic use and frequency of use are associated with this phenomenon (Rivas, Fernández, \& Gámez-Guadix, 2010). However, anyone can make use of new technologies in a professional way or even as a delight, the inconvenience arises when it is possible to feel comfort or relief (Echeburúa \& Corral, 2010).

Internet addiction is a phenomenon that is gaining more and more strength. Laconi, et al., (2014) perform a literary review of 
the multiple studies carried out to understand the level of addiction and the gratifications of the use of information technologies taken as reference in this study. Now, considering these circumstances, the purpose of the proposed research is to understand the behavior of the media on the Internet for students of public schools to which the state deploys low-medium resources, segmented by gender. In addition, it is intended to answer and substantiate the question: what are the factors that would be causing excessive Internet use and behavioral intervention in college students? In short, it aims to contribute to the academic-scientific area from the fields of technology and education.

\section{LITERARY REVIEW}

\subsection{Digital media behavior}

The Internet Network offers advantages used by all society, the intention of not using it should not be proposed, but rather the exploitation of its multiple scopes. It is manifested as an adequate environment for institutional and personal collaborative work, persuasion of interdisciplinary work, meeting space between academic components, easy and economic access (Bartau, Aierbe, \& Oregui, 2017).
The web maintains an almost infinite bank of information with this the electronic contents give birth to an information society. Throughout history human beings have always wanted to communicate, before writing, graphic or oral; currently with the passage of time a new writing arises: the digitization of all types of information, the so-called texts and hypermedia that allow different ways of communicating in a complementary way to generate communicative competence (Mengual, Lloret, \& Roig, 2013; Aesaert, et al., 2014).

Despite the extensive field covered by ICT, access has become a relevant cause of exclusion (Tirado-Morueta, Mendoza-Zambrano, Aguaded-Gómez \& Marín-Gutiérrez, 2016). According to several pieces of research, people with more economic resources access the Internet more easily, therefore they cover mainly the communication and information needs; On the other hand, people with limited economic resources have more difficulties in accessing information and perhaps professional improvement, which is why different personal behaviors and different operational skills are established. Below is a summary of the research conducted on the Internet (Table 1).

Table 1. Investigations on Internet abuse

\begin{tabular}{|c|c|c|c|c|}
\hline Scale & Autor & Theoretical basis & Country & $\alpha$ \\
\hline Adolescent Computer Addiction Test (ACAT) & Siomos, 2009 & Pathological gambling & Greece & .93 \\
\hline Adolescent Pathological Internet Use Scale (APIUS) & Lei \& Yang, 2007 & Cognitive-behavioral theory & China & $\begin{array}{r}.80 \\
.94\end{array}$ \\
\hline $\begin{array}{l}\text { Checklist for the Assessment of Internet and Computer game } \\
\text { Addiction (AICA-C) }\end{array}$ & Wolfling, 2010 & Substance dependence & Germany & .89 \\
\hline \multirow{6}{*}{ Chen Internet Addiction Scale (CIAS) } & \multirow{6}{*}{ Chen, 2003} & \multirow{6}{*}{$\begin{array}{l}\text { Substance dependence and } \\
\text { pathological gambling }\end{array}$} & China & .93 \\
\hline & & & Taiwan & .94 \\
\hline & & & Turkey & .94 \\
\hline & & & Iran & .93 \\
\hline & & & China & .93 \\
\hline & & & China & \\
\hline \multirow{2}{*}{ Chinese Internet Addiction Inventory (CIAI) } & \multirow{2}{*}{ Huang, 2007} & \multirow{2}{*}{ Pathological gambling } & \multirow{2}{*}{ China } & 0.80 \\
\hline & & & & .90 \\
\hline \multirow{7}{*}{ Compulsive Internet Use Scale (CIUS) } & \multirow{7}{*}{ Meerkerk, 2009} & \multirow{7}{*}{$\begin{array}{l}\text { Substance dependence and } \\
\text { pathological gambling }\end{array}$} & Netherlands & .89 \\
\hline & & & Iran & .89 \\
\hline & & & France & .85 \\
\hline & & & Switzerland & .78 \\
\hline & & & Germany & - \\
\hline & & & Germany & .92 \\
\hline & & & Germany & .90 \\
\hline Computer and Internet Use (CIU) & Pratarelli, 1999 & Substance dependence & USA & - \\
\hline Computer and Internet Use 2 (CIU-2) & Pratarelli \& Brown, 2002 & Substance dependence & USA & $\begin{array}{l}.57 \\
.89\end{array}$ \\
\hline Diagnostic Criteria of Internet Addiction (DC-IA) & Ko, 2005 & $\begin{array}{l}\text { Substance dependence and } \\
\text { pathological gambling }\end{array}$ & Taiwan & - \\
\hline \multirow{3}{*}{ Generalized Problematic Internet Use Scale (GPIUS) } & \multirow{3}{*}{ Caplan, 2002} & \multirow{3}{*}{ Cognitive-behavioral theory } & USA & $\begin{array}{r}.78 \\
85\end{array}$ \\
\hline & & & China & .91 \\
\hline & & & Iran & .90 \\
\hline
\end{tabular}


Internet Addiction Questionnaire (IAQ)

Internet Addiction Scale (IAS)

Internet Addiction Test (IAT)

Internet Related Addictive Behavior Inventory (IRABI)

Internet Related Problem Scale (IRPS)

Online Cognition Scale (OCS)

Problematic Internet Use Diagnostic-Interview (PIUD-I)

Problemactic Internet Use Scale (PIUS)

Virtual Addiction Survey (VAS)
Wang, 2001

Nichols \& Nicki, 2004

Brenner, 1997

Armstrong, 2000

Davis, 2002

Beard \& Wolf, 2001

Morahan-Martin \& Schumacher, 2000

Greenfield, 1999
Cognitive-behavioral theory

Australia $\quad .94$

Japan $\quad .85$

Canada $\quad .95$

Substance dependence

Turkey $\quad .92$

USA

Korea, South

UK

China

China

Switzerland $\quad .93$

Iran $\quad .88$

Pathological gambling

Finland $\quad .92$

Poland 93

UK

Germany

89

.91

Malaysia $\quad .91$

.83

.91

Greece -

Germany $\quad .89$

Spain $\quad .89$

Italia $\quad .91$

Lebanon $\quad .92$

Turkey $\quad .90$

Korea, South -

China $\quad .93$

Korea, South $\quad .91$

Japan $\quad .93$

Slovenia $\quad .91$

Bangladesh $\quad .89$

Canada $\quad .93$

China

Germany $\quad .89$

USA $\quad .87$

Australia $\quad .87$

.62

Substance dependence $\quad$ UK $\quad .84$

60

UK $\quad .60$

USA 94

Turkey 91

Cognitive-behavioral theory Croatia $\quad .94$

China $\quad .93$

USA $\quad .85$

Substance dependence USA -

Substance dependence $\quad$ USA $\quad .87$

$\begin{array}{lll}\text { Pathological gambling } & \text { USA }\end{array}$


The behavior of a person is based on the level of exploration that he or she has been able to maintain throughout their formal and informal learning. Generally speaking, the most active, neophylic or bolder people tend to be labeled as "explorers", while the more inactive, neophobic or more timid people tend to be labeled as "non-exploratory" (Réale et al., 2007). However, it has not been proven whether the "explorer" type actually collect more information during the learning process compared to those labeled "non-exploratory" (Toyokama, Saito \& Kameda, 2017).

Geffet \& Blau (2016) mention that "Behavior is a strictly physical, recordable and verifiable process, which consists, precisely, of being the activity by which a living being maintains and develops its life in relation to its environment, responding to it and modifying it. "For its part, the Royal Spanish Academy (RAE, 2010) highlights that addictive behavior becomes a "dependence of substances or activities harmful to health or psychic balance, extreme hobby to someone or something." In response, the World Health Organization (WHO) states that "an addiction is a physical and psycho-emotional disease that creates a dependency or need for a substance, activity or relationship, it is characterized by a set of signs and symptoms, in those that involve biological, genetic, psychological and social factors ". According to the aforementioned, it can be considered as a progressive pathology determined by uncontrolled time spaces, change of thought and denial of actions performed. There are criteria that allow us to deduce if a person maintains a physical and psychological dependence on any activity or element, which are:

- Constant desire or feeling of need about a substance or activity.

- Not being able to control the action or consumption.

- Attempt to abstain in order to reduce the addictive action.

- Constantly abandoning interests over other people: family or friends.

- Persistence in the use of the substance or activity.

That is, when talking about addiction, there are several tolerance and abstinence phenomena, in such a way that the person who is permanently intoxicated or in activity, shows a demand for consuming the substance or carrying out preferential activities, it is evidently difficult or impossible to interrupt or modify consumption and present an absolute determination (Stevens et al, 2014). Based on the scoop of Griffiths (2012), which states that there are clinical criteria that could lead to the homogeneous adaptation between a chemical and behavioral addiction, the author synthesizes the following measurement parameters:

- Salience or Priority in any activity that overwhelms feelings, thoughts and behaviors.

- Change in humor.

- Tolerance.

- Withdrawal or discomfort syndrome when the practice of an activity is reduced.

- Intra-psychic conflicts.

- Relapse.

\subsubsection{Intergenerational media culture}

Societies are cultural constructs, Castells (2014) defines culture as: "a set of values and beliefs that shape, guide and motivate the behavior of people", therefore, the present technological society should identify its culture as a historical indicator of transition, considering that it is a global network and works in a multipluricultural way integrating different areas of the world.
Cultural identity maintains an ideological autonomy that sometimes contrasts and resists changes. More than the emergence of a global homogeneous culture, what can be observed is historical and cultural diversity; therefore, the communication protocols between different cultures come to convert and integrate society into a Network, because without them it was not possible (Castells, 2014).

Prensky (2001) considers that the digitized society or Network has among its allies, adolescents and young people, establishing generations of use by means of final letters of the alphabet: generation "X" born between 1971 and 1985 adapted with difficulty to the technological age, generation "And" people who have grown up with the Internet and do not consider it as a prosthesis, born between 1985 and 1992 and on the other hand the "Z" generation, born after 1992, are called digital natives who from very young coexisted with the Internet and the Propagation of use of ICT. Although the new digital generations have a great capacity to handle electronic devices, they have difficulties in managing information (Colás, González, \& de Pablos, 2013, Andreassen et al., 2016).

Many terms have been added since Prensky (2001) mentions digital natives, among them: Generation Z, Generation V (Virtual), Generation C (by community or content), Silent Generation, Internet Generation or Generation Google that incorporates to ICT in their daily lives (Fernández \& Fernández, 2016).

\section{METHOD}

The method applied in the present study is focused quantitatively with a descriptive-exploratory investigation that bases a description of the studied topics. An experimental design is applied in the analysis of results evidenced in the manuscript. Likewise, the data analysis techniques used were; bibliographic analysis, statistical analysis and measurement of results.

The present investigation has been carried out with a random non-probabilistic sample of $n=773$ students of tertiary education corresponding to ISCED 6 (International Standard Classification of Education, UNESCO, 2011) in seven schools of the Province of Santo Domingo de los Tsáchilas - Ecuador, to the last grade of baccalaureate, $n=414$ men (53.6\%) and $n=359$ women (46.4\%).

The proposed study hypothesis is:

H1: The frequency of Internet use increases the loss of control and interferes with the academic-social life of college students.

\subsection{Process}

An electronic version of the questionnaire was designed in Google forms and the public education units were visited for two and a half months, sharing the link through the support of professors from each institution in person in the computer rooms. After the information collection process, the raw data was exported to an xls spreadsheet for subsequent importation and statistical processing in the SPSS software.

\subsection{Instrument}

For the present investigation, the scale determined by Young (1996), pioneer in investigating Internet addiction, has been chosen, the Internet Addiction Test (IAT) scale is the commonly used diagnostic instrument as shown in Table 1, based on the criteria of the DSM-V (Diagnostic and Statistical Manual of Mental Disorders), adapted to different languages (Alavi et al, 2010; Barke, Nele, \& Kröner-Herwig, 2012; Chang \& Law, 2008; Chong, Saramah, Subash, \& Manveen, 2012; Estévez, Bayón, de la Cruz, 
\& Fernández, 2009; Khazaal et al., 2008). The instrument has 20 items on a Likert scale ( 0 never, 1 rarely, 2 occasionally, 3 frequently, 4 often and 5 always); Young (1998) states that the total score ranges between 20 and 49 points determine that the user is online with controlled Internet use, those who maintain a score between 50 and 79 are in the category of problematic Internet use and from 80 to 100 points have significant problems in life due to the use of the Internet, that is to say, they present symptoms of abusive use.

The IAT scale which maintains an alpha of Cronbach .94, aims to measure the level of Internet abuse of students of tertiary education colleges in their daily routine, social life, use, academy and feelings (Barke, Nyenhuis, \& Kröner-Herwig, 2012). Factor analysis revealed a stable two-factor solution: use of the Internet and loss of control and interference with life, which fit with several investigations (Watters, Keefer, Kloosterman, Summerfeldt, \& Parker, 2013, Hawi NS, 2013, Khazaal et al., 2008).

\subsection{Principal component analysis}

To determine the main components (PAC) of IAT, a pilot test has been applied in the population to be investigated, verifying a Kaiser-Meyer-Olkin sample adequacy with $\mathrm{KMO}=, 88$ result that indicates an acceptable adequacy. The results obtained define two factors (Table 2). The determination of the factors of the main components was accompanied by a Varimax rotation and the results of the Bartlett sphericity test are $(x 2(253)=1302.30$, $\mathrm{p}=0.000)$.

\subsubsection{Factor 1: Internet use}

The first dimension includes elements on the constancy of use of the Internet and its emotional effect, referring to the state that a person who exceeds an incorrect use of the Internet may have, which could lead to levels of emotional instability that would disturb the cognitive development of a person, causing them to feel depressed, empty, nervous and even aggressive (Escrivá, García \& Navarro, 2002). The questions that make up the factor are: $17,15,13,11,9,19,7,5,3$.

\subsubsection{Factor 2: Loss of control and interference with life}

The second dimension considers that the loss of control refers to failed attempts to stop online time and the harmful consequences of using the Internet to fulfill activities (Barke, Nyenhuis, \& Kröner-Herwig, 2012; Faraci et al., 2013). In the analysis, the questions that refer to this dimension are; $14,16,18,12,20,4$, $2,10,8,6,1$.

Table 2. Matrix of rotated factors

\begin{tabular}{|c|c|c|}
\hline & \multicolumn{2}{|c|}{ Factor } \\
\hline & 1 & 2 \\
\hline 17. Do you try to hide how much time you really spend browsing? & 0,857 & \\
\hline 15. Has it ever happened to say "just a few more minutes" before turning off the computer or mobile device? & 0,755 & \\
\hline 13. How often do you lose hours of sleep by going online? & 0,734 & \\
\hline 11. Do you fear that your life without Internet will be boring and empty? & 0,711 & \\
\hline 9. Do you evade your real-life problems by spending some time connected to the Internet? & 0,631 & \\
\hline 19. Do you feel anxious, nervous, depressed or bored when you are not connected to the Internet? & 0,622 & \\
\hline 7. Is your academic productivity impaired by the use of the Internet? & 0,606 & \\
\hline 5. Is your academic activity (school, university) impaired because you spend too much time navigating? & 0,48 & \\
\hline 3. Do you prefer to get excited with photos or videos on the Internet instead of getting intimate with your partner? & 0,471 & \\
\hline 14. Are you often thinking about things related to the Internet when you are not connected? & & 0,813 \\
\hline 16. Have you ever tried to spend less time connected to the Internet and have not succeeded? & & 0,753 \\
\hline 18. Do you prefer to spend more time online than with your real-life friends? & & 0,729 \\
\hline 12. Do you feel upset when someone interrupts you while you are surfing? & & 0,664 \\
\hline 20. How often do new relationships form with other online users? & & 0,625 \\
\hline 4. How often do people around you reproach you that you spend too much time on the Internet? & & 0,554 \\
\hline 2. Do you neglect academic work by spending more time in front of the computer while surfing? & & 0,539 \\
\hline 10. Are you ever thinking about what you are going to do the next time you connect to the Internet? & & 0,536 \\
\hline 8. Do you become cautious or reserved when someone asks you what you spend the time you spend browsing? & & 0,369 \\
\hline 6. How often do you check the email before performing other priority tasks? & & 0,315 \\
\hline 1. How often do you find yourself carrying more time than you intended to be? & & 0,273 \\
\hline
\end{tabular}

Extraction method: Factorization of the main axis.

Rotation method: Varimax standardization with Kaiser. 


\section{RESULTS}

According to the achievement of results in this section, we proceed to perform the statistical treatment, which is part of the verification of the hypothesis. Subsequently we proceed to the descriptive and bivariate analysis to determine the scope of the research results.

H1: The frequency of Internet use increases the loss of control and interferes with the academic-social life of college students.

Determining a scale of three levels in the analysis of the first dimension (controlled level, medium advanced and advanced), it can be observed that $60.2 \%$ of the population operated maintains a controlled level of Internet use and $36.6 \%$ maintains a mediumadvanced level.

Therefore, the result adds regularity to the cognitive level of young school students because their openness to learning is not being affected due to the use of technologies, but it does mark a worrying percentage of advanced level in the analysis, as the tendency to grow, according to some authors mentioned above, it is eminent.

Table 3. Factor 1 analysis

\begin{tabular}{|c|c|c|c|c|c|}
\hline & & $\mathbf{F}$ & $\%$ & $\begin{array}{c}\text { Valid } \\
\%\end{array}$ & $\begin{array}{c}\text { Accumulated } \\
\%\end{array}$ \\
\hline \multirow{3}{*}{ Valid } & Checked & 450 & 58,2 & 60,2 & 60,2 \\
\hline & Pre-advanced & 274 & 35,4 & 36,6 & 96,8 \\
\hline & Advanced & 24 & 3,1 & 3,2 & 100 \\
\hline & Total & 748 & 96,8 & 100 & \\
\hline \multirow[t]{2}{*}{ Lost } & System & 25 & 3,2 & & \\
\hline & Total & 773 & 100 & & \\
\hline
\end{tabular}

Regarding the analysis of factor $1,73 \%$ of the determined sample maintains an advanced rate of loss of control and interference with life (table 4), however, to consider the level of significance, the correlation was carried out through Pearson between the two research variables.

Table 4. Factor 2 analysis

\begin{tabular}{|c|c|c|c|c|c|}
\hline & & $\mathbf{F}$ & $\%$ & $\begin{array}{c}\text { Valid } \\
\%\end{array}$ & $\begin{array}{c}\text { Accumulated } \\
\%\end{array}$ \\
\hline \multirow{3}{*}{ Valid } & Checked & 168 & 21,7 & 22,1 & 22,1 \\
\hline & Pre-advanced & 554 & 71,7 & 73 & 95,1 \\
\hline & Advanced & 37 & 4,8 & 4,9 & 100 \\
\hline \multirow{3}{*}{ Lost } & Total & 759 & 98,2 & 100 & \\
\hline & System & 14 & 1,8 & & \\
\hline & Total & 773 & 100 & & \\
\hline
\end{tabular}

After applying the Pearson Correlation, the result is shown in Table 5 that indicates that there is a correlation between variables 1 and 2, because the bilateral value is $p<0.05$ and the level of significance shows a "good correlation" $(, 625)$ according to Pearson's R and Rho index. Therefore, in response to the hypothesis, there is a good correlation between the use of the Internet and the loss of control and interference with life among students of public colleges in the region.
Table 5. Pearson correlation

\begin{tabular}{llll}
\hline & & Dimension 1 & Dimension 2 \\
\hline \multirow{2}{*}{ Dimension 1 } & Pearson correlation & 1 &, $625^{* *}$ \\
& Sig. (bilateral) & & 0 \\
& $\mathrm{~N}$ & 748 & 736 \\
& Pearson correlation &, $625^{* *}$ & 1 \\
Dimension 2 & Sig. (bilateral) & 0 & \\
& $\mathrm{~N}$ & 736 & 759 \\
\hline
\end{tabular}

${ }^{* *}$ The correlation is significant at the 0,01 (bilateral).

Finally, the descriptive analysis of items 18-20 of virtual friendships stand out, in which $34 \%$ frequently prefer to spend more time with their friends online than in real life and 33\% frequently make friendships online person to person.

Table 6. Do you prefer to spend more time online than with your real life friends?

\begin{tabular}{llllll}
\hline & F & \% & $\begin{array}{c}\text { Valid } \\
\mathbf{\%}\end{array}$ & $\begin{array}{c}\text { Accumulated } \\
\%\end{array}$ \\
\hline \multirow{4}{*}{ Valid } & Never & 64 & 8,3 & 8,3 & 8,3 \\
& Rarely & 40 & 5,2 & 5,2 & 13,5 \\
& Occasionally & 5 & 0,6 & 0,6 & 14,1 \\
& Frequently & 263 & 34 & 34 & 48,1 \\
& Often & 234 & 30,3 & 30,3 & 78,4 \\
& Always & 167 & 21,6 & 21,6 & 100 \\
& Total & 773 & 100 & 100 & \\
\hline
\end{tabular}

Table 7. How often do new relationships with other online users form?

\begin{tabular}{llllll}
\hline & F & $\mathbf{\%}$ & $\begin{array}{c}\text { Valid } \\
\mathbf{\%}\end{array}$ & $\begin{array}{c}\text { Accumulated } \\
\mathbf{\%}\end{array}$ \\
\hline \multirow{4}{*}{ Valid } & Never & 55 & 7,1 & 7,1 & 7,1 \\
& Rarely & 56 & 7,2 & 7,2 & 14,4 \\
& Occasionally & 34 & 4,4 & 4,4 & 18,8 \\
& Frequently & 254 & 32,9 & 32,9 & 51,6 \\
& Often & 228 & 29,5 & 29,5 & 81,1 \\
& Always & 146 & 18,9 & 18,9 & 100 \\
& Total & 773 & 100 & 100 & \\
\hline
\end{tabular}

It is important to emphasize that this phenomenon of abusive use of technologies could be affecting the social performance of adolescents in general, since the use of electronic devices constantly makes them lose personal or physical contact, which is why their preference for dialogue is reduced and their communication through digital resources increases. This produces more timid, less participatory young people inside and outside the classroom, without forgetting the digital risks to which they are exposed by the constant use of ICT.

\section{DISCUSSION}

According to the results obtained it could be determined in a general way that the use of Internet is more and more constant (Laconi, Chauchard, Girard, Rodgers, \& Chabrol, 2014). That 
is why the need for studies derived from this phenomenon are affecting the personal and academic life of adolescents, youth and adults. Considering the criterion of several authors, it is the smartphone, which is the electronic device that is being used by the entire population due to its multiple functionalities, including the Internet connection at anytime and anywhere. However, as mentioned by Odgerd (2018), it is not the frequency of use, but rather that they are using it, which generates concern, since applying a proper media literacy could generate e-learning benefits.

The behavior of a person is based on the level of exploration that he has been able to maintain throughout his formal and informal learning. Digital media behavior depends on the level of social influence perceived by a person, it would be considered part of associative learning and is based on social cognitive theory which mentions that the environment and behavior are the ones that influence actions (Bandura, 1977, Réale et al., 2007).

In the present investigation it is possible to demonstrate a correlation between the two variables presented with more than, 63 a good correlation could be determined. Therefore, the constant use of the Internet does influence the loss of control and therefore maintain an interference with the daily life of students. Its result worries, because that could be intervening in the academic-social development of a school student (Demetrovics \& Griffiths, 2012). However, this type of studies should be expanded to generate more results for the benefit of the academy.

As part of the analysis of the research, the preference of friendship in the school students has been highlighted, the result mentions that they frequently prefer to spend more time with their friends online (34\%) and form more online friendships than in physical conversation, that conditions a personal relationship that is increasingly ephemeral (García-Umaña, 2017). In this investigation, it is evident in the medium degree of the above-mentioned, because only $15 \%$ do not prefer online friendships and more than $35 \%$ always do it. Joo \& Sang (2013) demonstrate two determining factors to measure the motivations for the use of technologies, factor one: motivation of ritualized use that involves the dimensions of evasion, hobby, relaxation and entertainment, and factor two: motivation of instrumental use that attends to the dimensions of daily life, commercial information, news, work and learning, that is, cognitive processes, as mentioned before, in this research it was intended to address part of the two.

In the results, the target audience could not be labeled as addicted to the Internet, but with a degree of abusive or uncontrolled use of the Internet by school teenagers (Carbonell, Fuster, Chamarro, \& Oberts, 2012; Rivas, Fernández, \& Gámez-Guadix, 2010). To diagnose this phenomenon, one could consider expanding research dimensions and qualitative resources so as not to allow hasty deductions.

\section{CONCLUSIONS}

It is essential to apply educational measures to promote the responsible use of the Internet, it is unquestionable that information technologies are gaining strength in the information society and preferably among adolescents who will be the future of society. Prohibition could not be considered an option, regulating and encouraging research in the Network would become a resource with more academic input.

Latin America, according to the World Economic Forum (2015), is delayed compared to the European continent; however, North America maintains a remarkable percentage of worldwide connectivity with interesting characteristics in all areas. In the 2016 report of the International Telecommunication Union (ITU),
Ecuador is considered as a medium developing country, which is why the demand for regulatory policies is essential for a global positioning, economic and social growth.

The target audience of the research, despite maintaining a low appellation of resources, understands that they have access to the Internet every day; their access could be facilitated by operator plans or domiciliary contracts, motivated by communication networks. An important reflection is developed in terms of accessibility and a variable per capita.

\section{REFERENCES}

Alavi, S. S., Eslami, M., Maracy, M. R., Najafi, M., Jannatifard, F., \& Rezapour, H. (2010). Psychometric properties of Young Internet Addiction Test. Journal of Behavioral Sciences, 4(3), 185-189. Retrieved from https:/ goo.gl/MSXX2p

Aesaert, K., Van Nijlen, D., Vanderlinde, R., \& van Braak, J. (2014). Direct measures of digital information processing and communication skills in primary education: Using ítem response theory for the development and validation of an ICT competence scale. Computer \& Education, 76, 168181. doi:10.1016/j.compedu.2014.03.013

Aesaert, K., Van Nijlen, D., Vanderlinde, R., Tondeur, J., Devlieger, I., \& van Braak, J. (2015). The contribution of pupil, classroom and school level characteristics to primary school pupils' ICT competences: A performance-based approach. Computer \& Education, 87, 55-69. doi:10.1016/j.compedu.2015.03.014

Andreassen, C. S., Billieux, J., Griffiths, M. D., Kuss, D. J., Demetrovics, Z., Mazzoni, E., \& Pallesen, S. (2016). The relationship between addictive use of social media and video games and symptoms of psychiatric disorders: A large-scale cross-sectional study. Psychology Of Addictive Behaviors, 30(2), 252-262. doi:10.1037/adb0000160

Bartau, I., Aierbe, A., \& Oregui, E. (2017). Mediación parental del uso de Internet en el alumnado de Primaria: creencias, estrategias y dificultades [Parental mediation of the Internet use of Primary students: beliefs, strategies and difficulties]. Comunicar, 54(1), 1-11. doi:10.3916/C54-2018-07

Bandura, A. (1977). Social learning theory. Oxford, England: PrenticeHall.

Barke, A., Nele, N., \& Kröner-Herwig, B. (2012). The German Version of the Internet Addiction Test: A Validation Study. Cyberpsychology Behavior and Social Networking, 15(10), 534-542. doi:10.1089/cyber.2011.0616

Billieux, J., \& Van der Linden, M. (2012). Problematic use of the internet and self regulation: A review of the initial studies. The Open Addiction Journal, 5, 24-29. Retrieved from https://goo.gl/0qzYrk

Brand, M., Young, K. S., \& Laier, C. (2014). Prefrontal control and Internet addiction: A theoretical model and review of neuropsychological and neuroimaging findings. Frontiers in Human Neuroscience, 8, 375, 1-13. doi:10.3389/fnhum.2014.00375

Carbonell, X., Fúster, H., Chamarro, A., \& Oberst, U. (2012). Adicción a internet y móvil: una revisión de estudios empíricos españoles. Papeles del Psicólogo, 33(2), 82-89. Retrieved from https://goo.gl/S36wN0

Castellanos, A., Sánchez, C., \& Calderero, J. F. (2017). Nuevos modelos tecnopedagógicos. Competencia digital de los alumnos universitarios. Revista Electrónica de Investigación Educativa, 19(1), 1-9. Retrieved from http://redie.uabc.mx/redie/article/view/1148

Castells, M. (2014). Comunicación y poder. Madrid, España: Alianza Editorial.

Chang, M., \& Law, S. (2008). Factor structure for Young's Internet Addiction Test: A confirmatory study. Computers in Human Behavior, 24(6), 2597-2619. Retrieved from https://goo.gl/e41SKk

Chong, N., Saramah, I., Aili, H., Subash, P., \& Manveen, S. (2012). Validity of the Malay Version of the Internet Addiction Test: A Study on a Group of Medical Students in Malaysia. Asia-Pacific Journal of Public Health, 20(10), 1-10. doi:10.1007/s11126-013-9282-2

Colás, P., González, T., \& de Pablos, J. (2013). Juventud y redes sociales: Motivaciones y usos preferentes. [Young People and Social Networks: Motivations and Preferred Uses]. Comunicar, 40, 15-23. doi:10.3916 C40-2013-02-01

Colás-Bravo, P., Conde-Jimenez, J., \& Reyes-de Cózar, S. (2017). Competencias digitales del alumnado no universitario [Digital competences of non-university student]. RELATEC, 16(1), 7-20. doi:10.17398/1695288X.16.1.7

Demetrovics, J., \& Griffiths, M.D. (2012). Behavioral addictions: Past, present and future. Journal of Behavioral Addictions 1(1), 1-2. doi:10.1556/ JBA.1.2012.1.0

Echeburúa, E., \& Corral, P. (2010). Addicion to new technologies and to online social networking in young people: A new challenge. Adicciones, 22(3), 91-95. Retrieved from https://goo.gl/EGd225 
Escrivá, M. V., García, P. S., \& Navarro, M. D. (2002). Procesos cognitivos y emocionales predictores de la conducta prosocial y agresiva: La empatía como factor modulador. Psicothema, 14(2), 227-232. Retrieved from https://goo.gl/BYSpJM

Estévez, L., Bayón, C., de la Cruz, J., \& Fernández-Líria, A. (2009). Uso y abuso de Internet en adolescentes. En E. Echeburúa, F. J. Labrador, \& E. Becoña (Eds.), Adicción a las nuevas tecnologías (pp. 101-130). Madrid: Pirámide.

Faraci, P., Craparo, G., Messina, R., \& Severino, S. (2013). Internet Addiction Test (IAT): Which is the best factorial solution? Journal of Medical Internet Research, 15(10), 225-236. doi:10.2196/jmir.2935

Fernández, F. J., \& Fernández, M. J. (2016). Los docentes de la Generación Z y sus competencias digitales [Generation Z's Tea chers and their digital skills]. Comunicar, 46, 97-105. doi:10.3916/C46-2016-10

García-Umaña, A. (2017). Impacto social y educativo del comportamiento mediático digital contemporáneo: Nomofobia, causas y consecuencias. Dilemas contemporáneos, 5(1), 1-21. Retrieved from https://goo.gl/GLuXvd

Geffet, M., \& Blau, M. (2016). Cross-generational analysis of predictive factors of addictive behavior in smartphone usage. Computer in Human Behavior, 64(1), 682-693. doi:10.1016/j.chb.2016.07.061

Griffiths, M. D. (2012). Internet sex addiction: A review of empirical research Addiction Research \& Theory, 20(2), 111-124. doi:10.3109/16066359 .2011 .588351

Griffiths, M. D. (2005). A 'components' model of addiction within a biopsychosocial framework. Journal of Substance Use, 10(4), 191-197. Retrieved from https://goo.gl/WM3sal

Hawi, N. S. (2013). Arabic validation of the Internet addiction test. Cyberpsychol Behav Soc Netw, 16(3), 200-204. doi:10.1089/cyber.2012.0426

ITU (International Telecomunication Union). (2016). Measuring the information society report. Geneva, Switzerland: International Telecommunications Union.

Jiménez-Albiar, M. I., Piqueras, J. A., Mateu-Martínez, O., Carballo, J. L., Orgilés, M., \& Espada, J. P. (2012). Diferencias de sexo, característica de personalidad y afrontamiento en el uso de internet, el móvil y los videojuegos en la adolescencia. Health and Adicctions/Salud y Drogas, 12(1), 61-82. Retrieved from https://goo.gl/ghYRFv

Joo J., \& Sang Y. (2013). Exploring Koreans' smartphone usage: An integrated model of the technology acceptance model and uses and gratifications theory. Computer in Human Behavior, 29, 2512-2518. Retrieved from https://goo.gl/e2dGAV

Khazaal Y., Billieux J., Thorens G., Khan R., Louati \&, Scarlatti E., Theintz F., Lederrey J., Van Der Linden M., \& Zullino D. (2008). French validation of the Internet addiction test. Cyberpsychol Behavior, 11(6), 703-706. doi:10.1089/cpb.2007.0249

Laconi, S., Chauchard, E., Girard, M., Rodgers, R. F., \& Chabrol, H. (2014). The measurement of Internet addiction: A critical review of existing scales and their psychometric properties. Computers in Human Behavior, 41(1), 190-202. Retrieved from https://goo.gl/kcXUJy

Mengual-Andrés, S., Lloret, C., \& Roig, R. (2013). Validación del Cuestionario de evaluación de la calidad de cursos virtuales adaptado a MOOC. RIED, 18(2), 145-169. Retrieved from https://goo.gl/Q1NSKT

Odgerd, C. (2018). Smartphones are bad for some teens, not all. Nature, 555(7698), 432-580. doi:10.1038/d41586-018-02109-8

Prensky, M. (2001). Digital Natives, Digital Immigrants. On the Horizon, 9(5), 1-6. Retrieved from http://goo.gl/93tth3

Real Academia de la Lengua Española. (2010). Diccionario de la Lengua Española. Retrieved from http://www.rae.es/

Réale, S. M. Reader, D., Sol, P. T., \& McDougall, N. J. (2007). Dingemanse Integrating animal temperament within ecology and evolution Biological Reviews, 82, 291-318. doi:10.1111/j.1469-185X.2007.00010.x

Ruiz-Olivares, R., Lucena, V., Pino, M. J., \& Herruzo, J. (2010). Análisis de comportamientos relacionados con el uso/abuso de Internet, teléfono móvil, compras y juego en estudiantes universitarios. Adicciones, 22(4), 301-310. Retrieved from: https://goo.gl/9M76hD

Stevens, L., Verdejo-García, A., Goudriaan, A. E., Roeyers, H., Dom, G., \& Vanderplasschen, W. (2014). Impulsivity as a vulnerability factor for poor addiction treatment outcomes: a review of neurocognitive findings among individuals with substance use disorders. The Journal of Substance Abuse Treatment, 47(1), 58-72. doi:10.1016/j.jsat.2014.01.008

Tirado-Morueta, R., Mendoza-Zambrano, D., Aguaded-Gómez, J. I., \& MarínGutiérrez, I. (2016). Empirical study of a sequence of access to Internet use in Ecuador. Telematics and Informatics, 34(4), 171-183. doi:10.1016/j.tele.2016.12.012

Toyokama, W., Saito, Y., \& Kameda, T. (2017). Individual differences in learning behaviours in humans: Asocial exploration tendency does not predict reliance on social learning. Evolution and Human Behavior, 38(3), $325-$ 333. doi:10.1016/j.evolhumbehav.2016.11.001
UNESCO. (2011). International Standard Classification of Education ISCED. Montreal: Canadá. Retrieved from https://goo.gl/gcy6Nt

Watters, C. A., Keefer, C. V., Kloosterman P. H., Summerfeldt, L. J., \& Parker J. A. (2013). Examining the structure of the Internet Addiction Test in adolescents: A bifactor approach. Computers in Human Behavior, 29(6), 2294-2302. doi:10.1016/j.chb.2013.05.020

Young, K. S. (1996). Psychology of computer use: XL. Addictive use of the Internet: A case that breaks the stereotype. Psychological Reports, 79(3), 899902. doi:10.2466/pr0.1996.79.3.899

How to cite this article: García-Umaña, A. (2018). Digital Media Behavior of School Students: Abusive Use of the Internet. Journal of New Approaches in Educational Research, 7(2), PP. 140-147. doi: 10.7821/ naer.2018.7.284 